\title{
Study on the Damping of Multi-layer U Bellows Based on ANSYS
}

\author{
Dongying $\mathrm{Li}^{1,}$, , Yonggang $\mathrm{Liu}^{2, \mathrm{~b}}$ and Shengjie $\mathrm{Cao}^{3, \mathrm{c}}$ \\ ${ }^{1}$ Henan University of Science and Technology, China \\ ${ }^{2}$ Henan University of Science and Technology, China \\ ${ }^{3}$ Henan University of Science and Technology, China \\ alidyingly@163.com, bmartin_lyg@163.com, ‘446585219@qq.com
}

Keyboards: multi-layer bellows; loss factor; iterative method of modal strain energy; finite element model

\begin{abstract}
The relationship between wave length, diameter and number of layers and the loss factor of multi-layer bellows was analyzed by using the iterative method of modal strain energy, according to the numerical analysis results of the finite element ANSYS software, the influence curves of different parameters on the loss factor were obtained. The results show that: with bellows wave length and diameter increased, the loss factor are decreased; the loss factor increases with the increase of the number of layers. Finally, the correctness and validity of the finite element model and ANSYS numerical analysis were verified by the experimental method.
\end{abstract}

\section{Introduction}

Bellows are circular thin-walled shells with corrugations, which are axial symmetric. In the pipeline system, the load carrying surface from different directions and the bellows, the bellows itself can cause large displacement, so it is often used as displacement compensation, pipelines and equipment, sealing, vibration and flexible connection device, the bellows is a kind of common line components, currently in production and life everywhere, the bellows is widely used in the aerospace industry, petroleum chemical industry, water conservancy construction, electric power and other fields. Most of the use of the bearing capacity and small amount of compensation in the small parts of single tube, and through multiple shell combination in together to form a multi-layer bellows, there is large displacement compensation capacity, strength and flexibility.

In recent years, scholars at home and abroad have done a series of research work on bellows, while the research on bellows loss factor is not perfect enough. Therefore, in this paper, the influence of the wave distance, diameter and layer number on the loss factor is mainly studied for the U type multi-layer bellows.

\section{The loss factor analysis of bellows}

In the pipeline system, when the bellows vibrate, the viscoelastic damping material will dissipate part of the vibration energy, thus playing a role in vibration and noise reduction. The main index to measure the dissipation capacity of viscoelastic damping materials is the loss factor of materials, which is equal to the ratio of the dissipated energy and the total strain energy in the vibration period. The loss factor of the system can be solved by the modal strain energy theory. According to the modal strain energy theory and the variational principle, the formula of the loss factor of the order $r$ of the bellows is derived: 


$$
\eta^{(r)}=\frac{\sum_{j=1}^{l} \eta_{v} U_{v j}}{\sum_{i=1}^{n} U_{i}}
$$

Where $\eta_{v}$ is loss factor of multi-layer bellows. $l$ is the number of elements in the damping sandwich. $n$ is the total number of bellows unit. $U_{v j}$ is the damping $\mathrm{j}$-th unit strain energy; $U_{i}$ is the i-th unit strain energy of the bellows.

\section{The construction of FEM model}

First to determine the unit types according to the nonlinear characteristics of structure and material of the bellows, the multi-layer bellows with solid186 solid element, the purpose is to combine damping layer, inner layer and the outer layer of the bellows layer. Secondly, the flange is simplified, and the mass unit mass 21 is used instead of the flange plate. The mapping method is adopted to divide the solid element mesh reasonably. Finally determine the multi-layer bellows boundary conditions, in order to more close to the actual engineering application, the multi-layer bellows boundary condition setting method for the end is a free end, the other end is a fixed end. As shown in Fig. 1, the established ANSYS model.

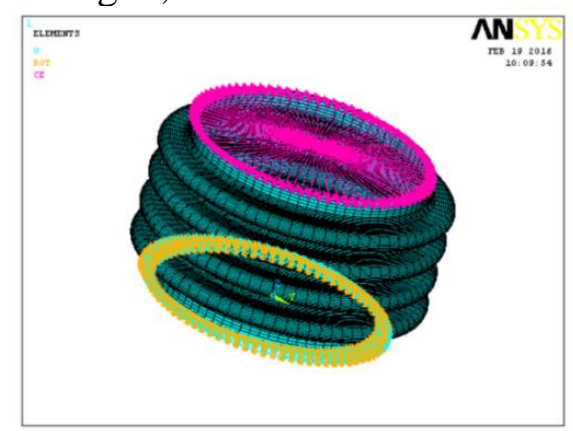

Fig. 1 the established ANSYS model

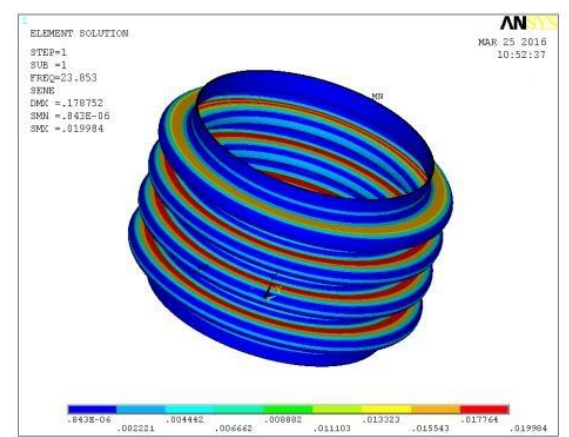

Fig. 2 The strain energy of viscoelastic material layer

\section{Effect of parameters of bellows on loss factor}

The wave length, diameter and layer number of bellows have a great influence on the loss factor. Therefore, the modal strain using APDL parametric language to the loss factor of axial iteration methods to solve the above built bellows finite element model of the first order, and the bellows wave length, diameter and number of layers and the relationship between the loss factor of bellows were discussed. The strain energy nephogram of viscoelastic material layer (shown in Fig.2). Fig. 3 shows the strain energy nephogram of bellows. Fig. 4 shows the axial first order mode diagram of bellows.

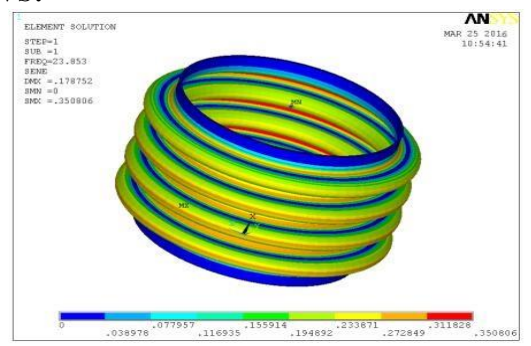

Fig. 3 the established ANSYS model

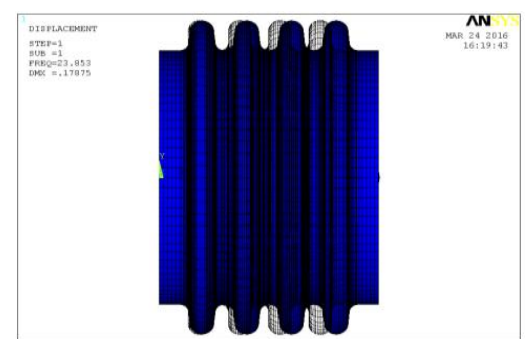

Fig. 4 the axial first order mode diagram of bellows 
Based on the multi-layer bellows configuration parameters affect the wave length and diameter on the loss factor of the damping material, if the thickness of $0.2 \mathrm{~mm}$, wave length and diameter were $24 \mathrm{~mm} \sim 36 \mathrm{~mm}$ and $94.5 \mathrm{~mm} \sim 119.5 \mathrm{~mm}$ in the range of multi-layer bellows, the variation of loss factor of multilayer bellows with different wave heights and diameters is analyzed by ANSYS. Fig. 5 shows the variation curve of loss factor with wave distance, Fig. 6 shows the variation curve of loss factor with diameter. As shown in Fig. 5 and Fig.6, the loss factor of multi-layer bellows has an inverse relation with the wave distance and diameter. With the increase of the wave distance and diameter, the loss factor shows a trend of attenuation. Therefore, in order to improve the vibration reduction and noise reduction capability of the multi-layer bellows, the wave pitch and diameter of the multi-layer bellows should be reduced as much as possible while meeting the processing conditions and working conditions.
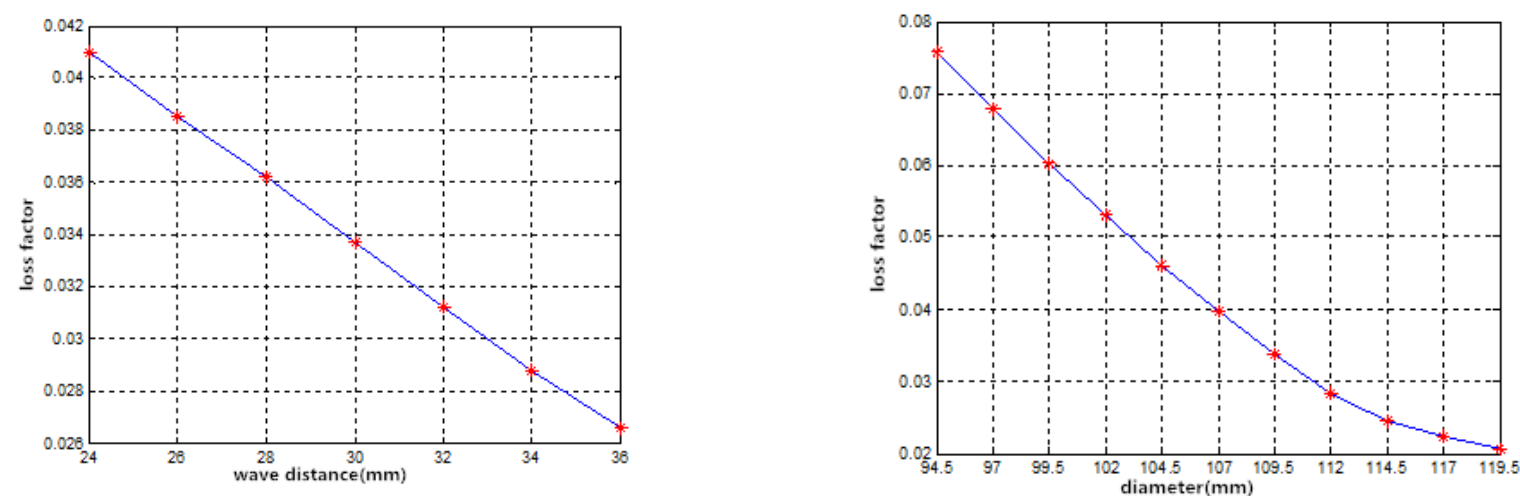

Fig. 5 the variation of loss factor with wave distance Fig. 6 the variation of loss factor with diameter

Considering the influence of the structure of corrugated tube on the loss factor, when the total thickness of the damping layer is the same, the number of layers of the bellows is changed. If the layers are three, five and seven layers, the relationship between the loss factor and the layer number of the multi-layer bellows is shown in figure 7. It can be seen that when the total thickness of the damping layer is the same, the loss factor becomes larger with the increase of the number of layers. Therefore, increasing the wave number appropriately can better strengthen the vibration and noise reduction ability of bellows.

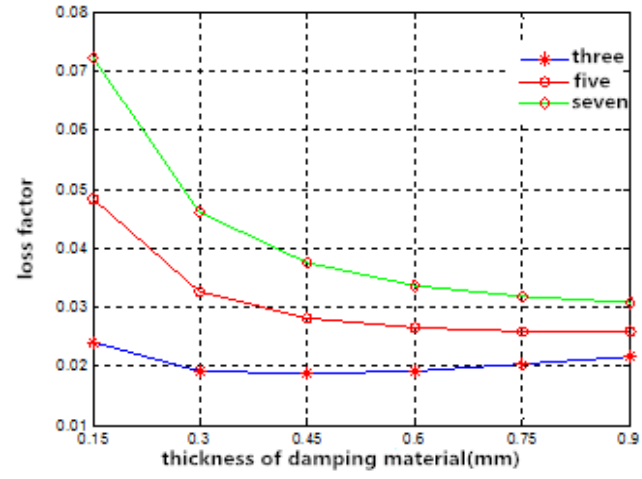

Fig. 7 the change of loss factor with number of layers

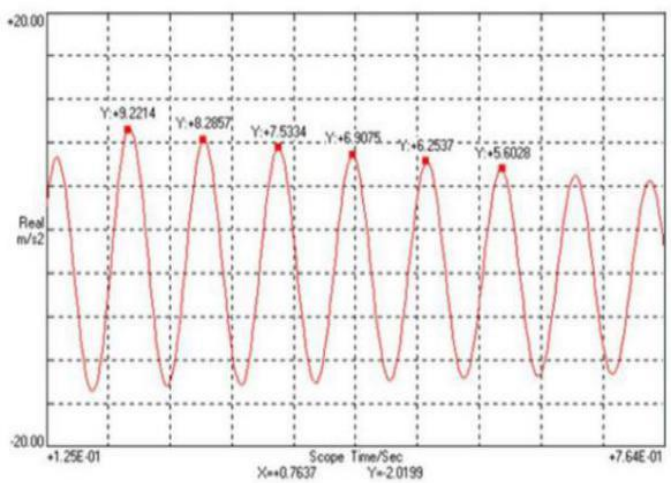

Fig. 8 the response signal in time domain

\section{Experimental study}

The excitation mode chosen in this paper is the transient excitation, and the experiment is carried out at a temperature of $25^{\circ} \mathrm{C}$. In the process of testing data processing, the digital signal is processed by digital signal processing instrument, and obtained the peak value of signal at two adjacent time points. The damping ratio coefficient of bellows is obtained by software analysis, the 
principle is as follows:

$$
\xi=\frac{\ln \left(\frac{\mathrm{X}_{i}}{\mathrm{X}_{i+1}}\right)}{\sqrt{4 \pi^{2}+\left(\ln \frac{\mathrm{X}_{i}}{\mathrm{X}_{i+1}}\right)^{2}}}
$$

The object of this experiment is a multi-layer bellows with sandwich damping. The beam is connected with the specimen by a rubber cap hammer and the beam is applied along the axial direction, so that the transient excitation signal is applied, and the excitation frequency is selected within the range of $0 \sim 200 \mathrm{~Hz}$, Fig.8 shows the response signal in time domain.

In order to obtain more accurate damping ratio coefficients of bellows, the damping ratio coefficients of six different time points of the transient response of the bellows are similar, which are used as the modal damping ratio coefficients of the bellows. The damping ratio coefficients of bellows in different time points are as follows:

$$
\bar{\xi}=\frac{1}{5} \sum_{i=0}^{4} \frac{\ln \left(\frac{\mathrm{X}_{i}}{\mathrm{X}_{i+1}}\right)}{\sqrt{4 \pi^{2}+\left(\ln \frac{\mathrm{X}_{i}}{\mathrm{X}_{i+1}}\right)^{2}}}
$$

There is a mathematical formula for the loss factor and damping ratio coefficient: $\bar{\eta}=2 \bar{\xi}$, so that the average value of the loss factor can be obtained.

$$
\bar{\eta}=\frac{2}{5} \sum_{i=0}^{4} \frac{\ln \left(\frac{\mathrm{X}_{i}}{\mathrm{X}_{i+1}}\right)}{\sqrt{4 \pi^{2}+\left(\ln \frac{\mathrm{X}_{i}}{\mathrm{X}_{i+1}}\right)^{2}}}
$$

The Table. 1 shows the bellows axial damping ratio identification. The Table. 2 shows the comparison of the theoretical analysis and test the actual value.

\begin{tabular}{|c|c|c|c|c|c|c|}
\hline $\begin{array}{c}\mathrm{X}_{i} \\
\mathrm{~m} / \mathrm{s}^{2}\end{array}$ & $\begin{array}{l}\mathrm{X}_{i+1} \\
\mathrm{~m} / \mathrm{s}^{2}\end{array}$ & $\xi$ & $\bar{\xi}$ & $\begin{array}{c}\text { experimental } \\
\text { mean }\end{array}$ & $\begin{array}{c}\text { calculation } \\
\text { result }\end{array}$ & error $(\%)$ \\
\hline 9. 2214 & 8. 2857 & 0.017026 & \multirow{5}{*}{0.015858} & \multirow{5}{*}{0.031716} & \multirow{5}{*}{0.03370} & \multirow{4}{*}{6.25} \\
\hline 8.2857 & 7. 5334 & 0.015147 & & & & \\
\hline 7. 5334 & 6.9075 & 0.013804 & & & & \\
\hline 6.9075 & 6. 2537 & 0.015824 & & & & \\
\hline 6. 2537 & 5. 6028 & 0.017490 & & & & \\
\hline
\end{tabular}

Table. 1 the bellows axial damping ratio identification

Table. 2 the error

\section{Conclusions}

This paper established the model of the bellows, and then through the study of bellows found: influence of multi-layer bellows wave length and diameter on the loss factor is as bellows wave length and diameter increase the loss factor are decreased linearly; the loss factor increases with the 
number of layers. Finally, the vibration test of bellows was carried out. The measured values of the test were basically the same as the theoretical analysis values, and the correctness of the finite element theory analysis was verified.

\section{References}

[1] MA W, LI D.Y, ZHONG Y.P. Development and Application of Bellows. Journal of Henan University of Science and Technology (Natural Science ),2004(04),p.28-31.

[2] TAN Z.J, CAO L.Y, LIAO R.D, et al. Finite Element Analysis of Axial Stiffness and Critical Load of Multi-layer U Bellows. Mechanical Strength,2004(01),p.49-53.

[3] CHEN W, WEN W.D. Finite Element Analysis Method Based on Structural Parameterization. Mechanical Science and Technology,2003(06),p.948-950.

[4] Belyaev A K,Zinovieva T B, Smirnov K K. Theoretical and Experimental Studies of the Stress-strain State of Expansion Bellows as Elastic Shells. Physics and Mathematics,2017(3),p.7-14.

[5] KIM J H,KIM J Y,JANG B G,et al.3-Dimensional Finite Element Analysis of a Vibrating Bellows with a Large Diameter. Key Engineering Materials, 2011,p.689-692.

[6] ZHU J.F. Study on Equivalent Stiffness of Multi-layer Bellows under Fluid Structure Interaction. edtied by D. Henan University of Science and Technology, CHINA(2011), in press.

[7] LIU Y.G, SI D.H, MA W,et al.Research on Stiffness and Damping of Sandwich Damping Metal Bellows Considering Fluid-solid Interaction. Journal of Mechanical Engineering,2014(05),p.74-81.

[8] GUO Y.J, LI H.Q, MENG G, et al. Finite Element Modeling and Experimental Study of Viscoelastic Free Layer Damping Tube. Vibration and Shock,2008(05),p.99-102+177. 